\title{
Development and Validation of a Moral Intelligence Measure for the Adolescent Children of Veterans
}

\section{ART I C LE INF O}

\section{Article Type}

Descriptive Study

\section{Authors}

Abadian A. ${ }^{1} M S C$

Robatmili S. ${ }^{2 *} P h D$
How to cite this article Abadian A, Robatmili S. Development and Validation of a Moral Intelligence Measure for the Adolescent Children of Veterans. Iranian Journal of War \& Public Health. 2020;12(3):181-188.
${ }^{1}$ Psychology Department, Humanities Faculty, Tehran Branch of Science and Research, Islamic Azad University, Tehran, Iran

${ }^{2}$ Janbazan Medical and Engineering Research Center, Tehran, Iran

\section{*Correspondence}

Address: Janbazan Medical and Engineering Research Center (JMERC), Tehran, Iran. Postal Code: 1985946563

Phone: +98 (21) 44865179

Fax: -

somayemili@yahoo.com

\section{Article History}

Received: December 22, 2019

Accepted: May 18, 2020

ePublished: March 03, 2021

\section{A B S T R A C T}

Aims War has many psychological and behavioral consequences for the veteran and other members of his family. Many factors, including moral intelligence, play a protective role against the psychological damage of these families. This study aimed to design and validate the psychometric properties of the moral intelligence measure for the adolescent children of veterans.

Instruments \& Methods For this descriptive correlational research with the experimentation approach, a sample of 325 adolescent girls and boys aged from 14 to 18 years living in Tehran in 2019, who were studying in the first and second secondary schools were selected using the available methods from regions 2 and 5. Then, from each of those areas, 4 schools (2 girls 'schools and 2 boys' schools) were selected by simple random sampling, and finally the students of 14 classes answered the designed moral intelligence questionnaire and Maslow's self-actualization. Exploratory factor analysis, Cronbach's alpha and Pearson correlation coefficient were used to design and validate the questionnaire's psychometric properties. Data using software SPSS 21 were analyzed.

Findings To extract the underlying factors of the 70-item Moral Intelligence Questionnaire, the Kaiser-Mir-Oliken (KMO) index was equal to 0.858, and the Bartlett spherical index was equal to 7208.51 and was statistically significant at the level of 0.01 . Based on the common meanings of the items, the first component was "maintaining the dignity of others", the second component was "adherence to principles", the third component was "moral sensitivity", the fourth component was "moral self-efficacy" and the fifth component was "ego empowerment". Based on Cronbach's alpha coefficients' results obtained more than 0.7 for the components and a positive and significant correlation coefficient $(\mathrm{p}<0.01)$, the questionnaire was reliable and valid.

Conclusion The Moral Intelligence Scale is a reliable and valid tool as a model for measuring moral intelligence in the adolescent children of veterans in Tehran concerning socio-cognitive changes in Iranian society.

Keywords Moral; Intelligence; Veterans

\section{I T A T I O N L I N K S}

[1] The Role of Religious Attitude in Coping with Psychological Distress and Emotion Regulation Difficulties ... [2] The effectiveness of shame management training based on PEGS program ... [3] Correlation of parental perception and its components with ... [4] Building moral intelligence: The seven essential virtues that teach kids ... [5] The step-bystep plan to building moral ... [6] Linking strong moral principles to business ... [7] Parentchild relationship trajectories during adolescence ... [8] Attachment quality and psychopathological symptoms in clinically ... [9] Maternal and paternal parenting styles associated with relational aggression in children and ... [10] Religion and HIV: A review of the literature and clinical ... [11] Parental factors associated with rumination related ... [12] Advances in the conceptualization and measurement ... [13] Transformational leadership and moral ... [14] Code of ethics: principles for ethical ... [15] Implications of inadequate parental bonding and peer victimization ... [16] The changing of the gods: abused Christian wives and their hermeneutic ... [17] Surveyors' perspectives on ethics in organizational ... [18] The moral intelligence of ... [19] Critique of self-actualization ... [20] Ethnic differences and motivation based on Maslow's ... [21] Investigating the needs of school principals in Tehran ... [22] Parents Do make a difference ... 
نكَرشهاى افراد نسبت به مسايل، باورهاى مذهبى، سرسختى

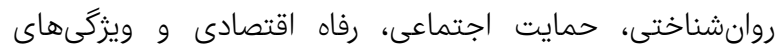

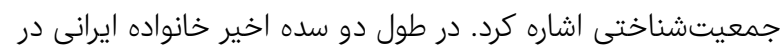

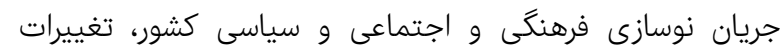

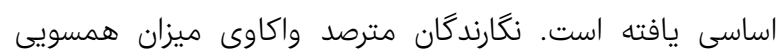

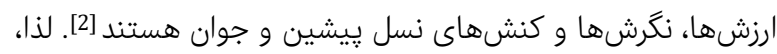

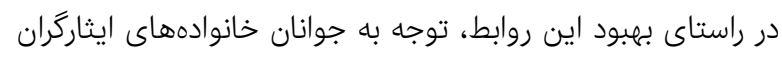

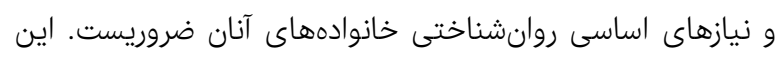

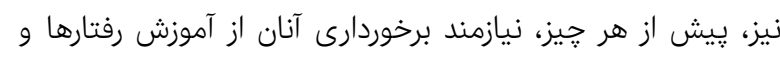

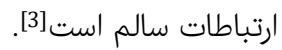

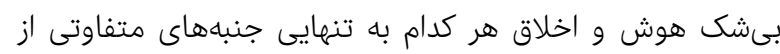

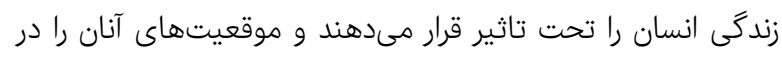

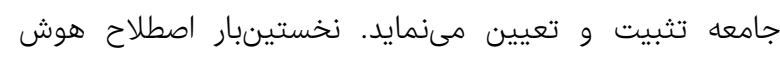

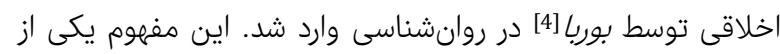

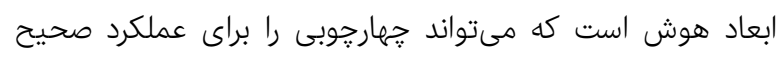

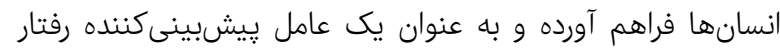

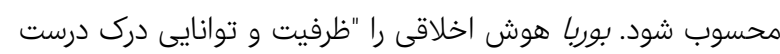

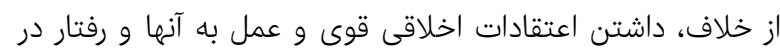

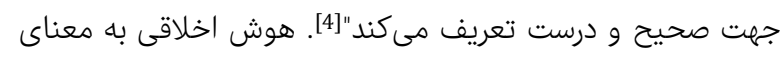

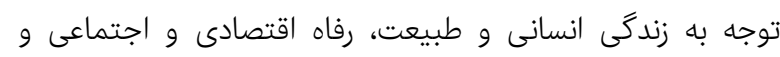

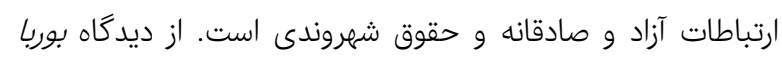

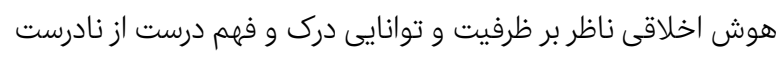

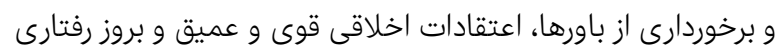

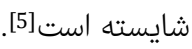

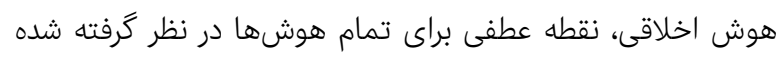

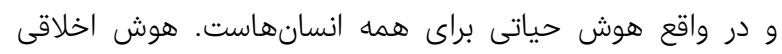

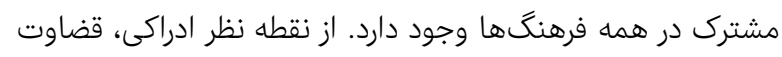

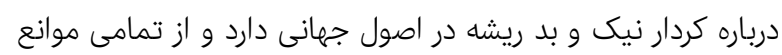

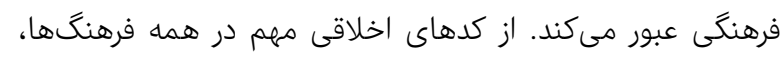

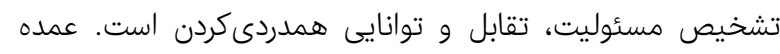

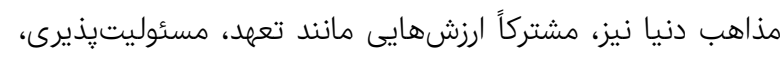

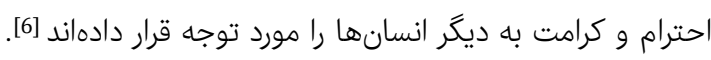

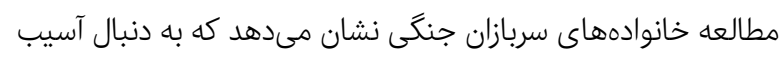

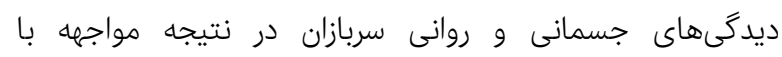

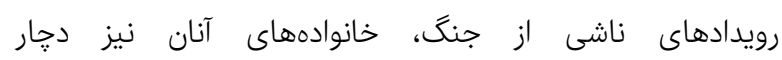

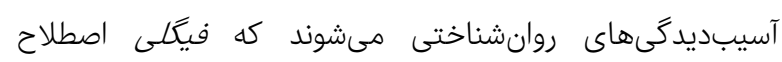

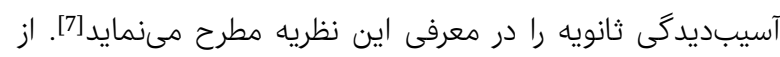

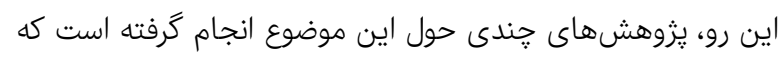

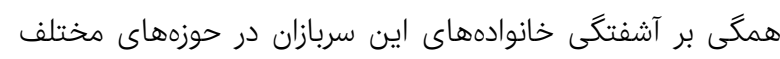

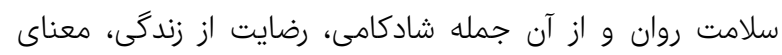

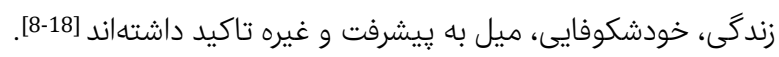

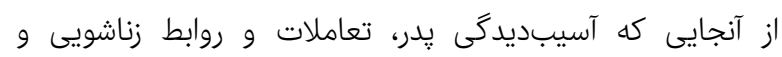

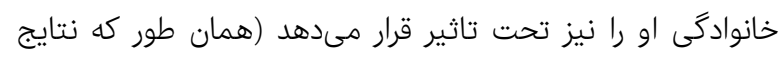
تحقيقات نيز مويد اين مطلب است)، مىتوان احتمال داد جنبهها
ساخت و رواسازى يرسشنامه هوش اخلاقى براى فرزندان نوجوان ايثارگران

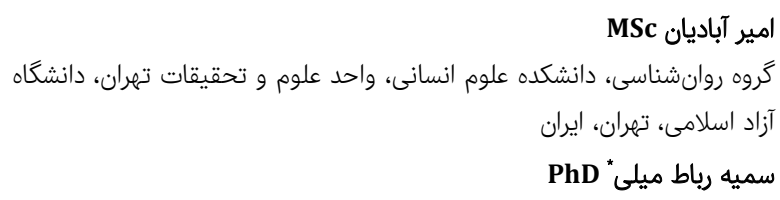

مركز تحقيقات مهندسى و علوم يزشكى جانبازان، تهران، ايران

جكيده اهداف: جنكَ بيامدهاى روانى و رفتارى متعددى براى فرد جانباز و ديكًر اعضاى

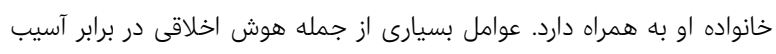

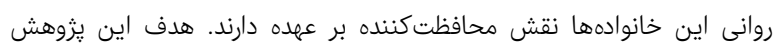

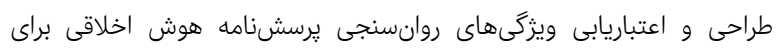
نوجوانان فرزند ايثارگر بود.

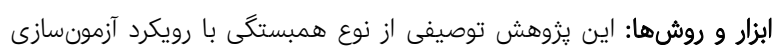

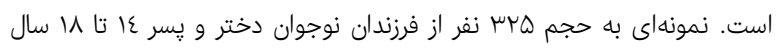

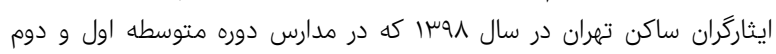

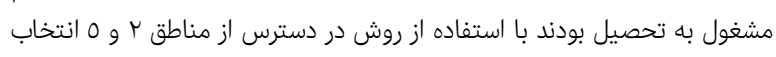

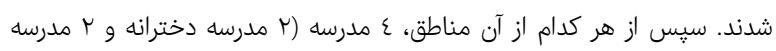

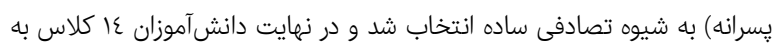

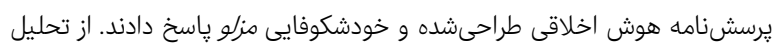

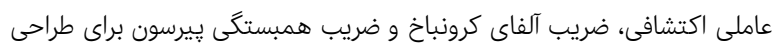

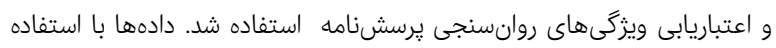

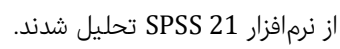

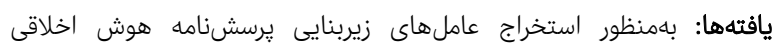

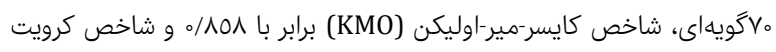

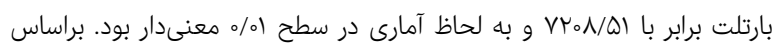

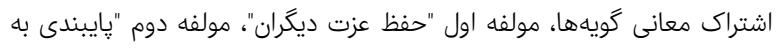

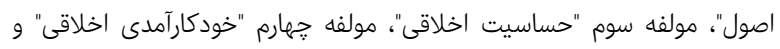

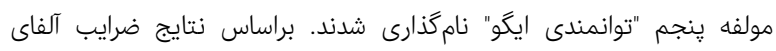

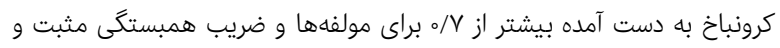

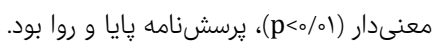

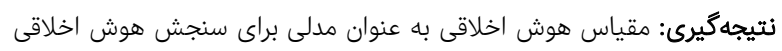

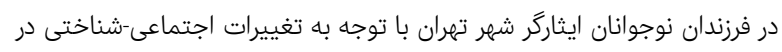

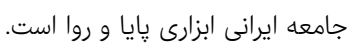

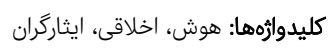

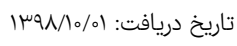

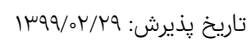

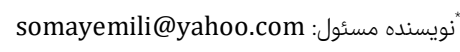

مقدمه

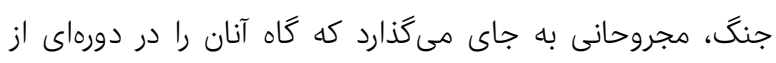

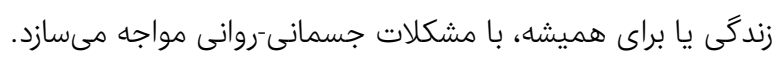

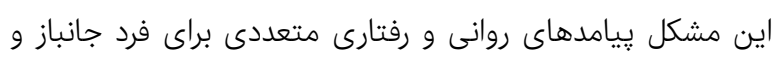

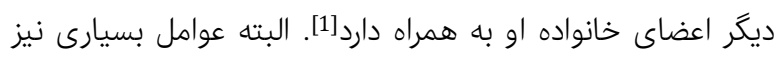

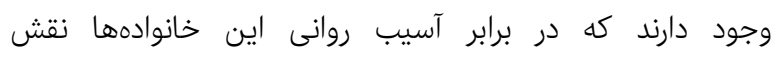

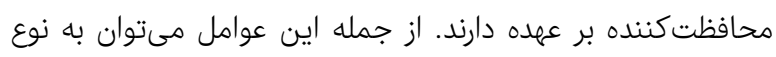




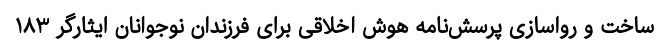

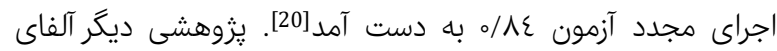

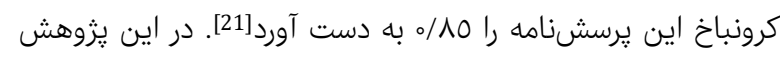

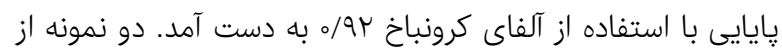

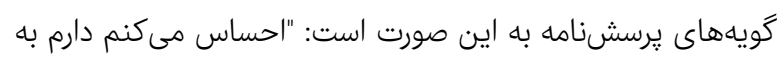

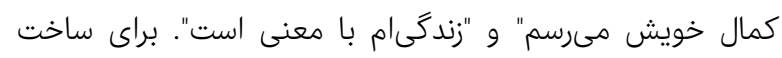

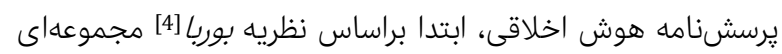

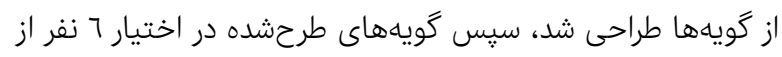
مدرسان روانشناسى، جامعهشناسى و فلسفه قرار گرفت و از از آنان

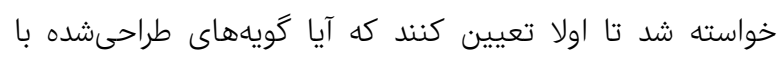
تعاريف ارايهشده از هوش اخلاقى مرتبط هستند؟ آيا گويههاى

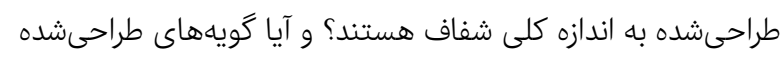

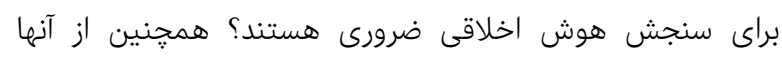

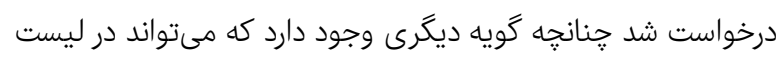

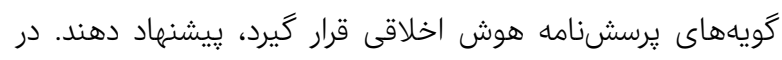

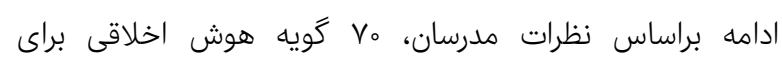

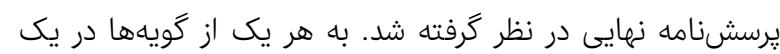

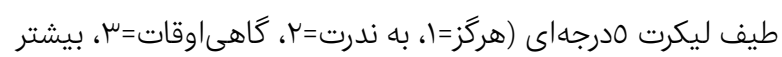

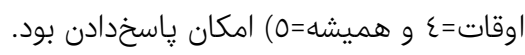

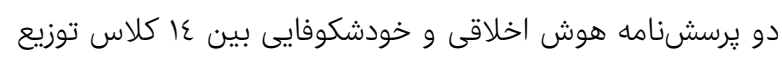

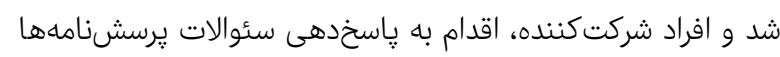

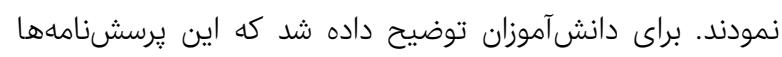

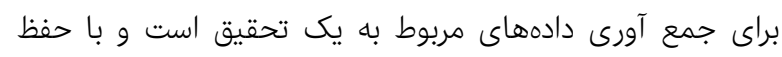

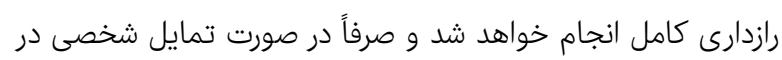
تحقيق شركت نمايند. روشهاى آمارى تحليل عاملى اكتشافى، ضريب آلفاى كرونباخ و

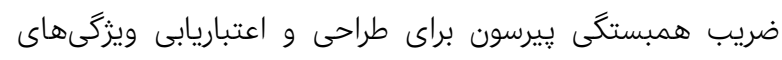

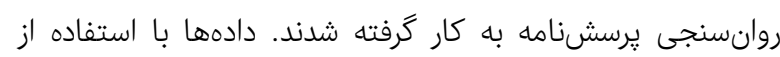

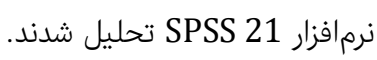

يافتهها

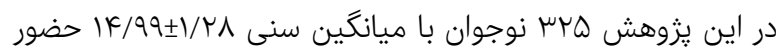

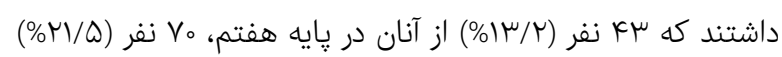

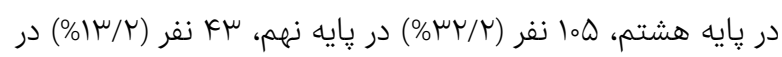

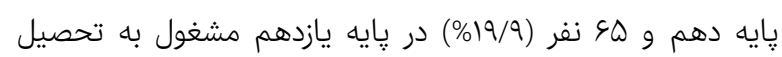

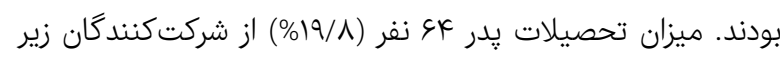

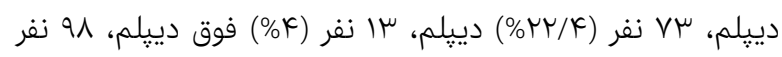

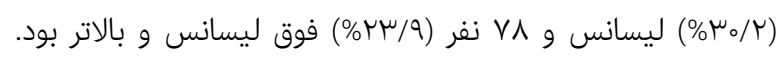

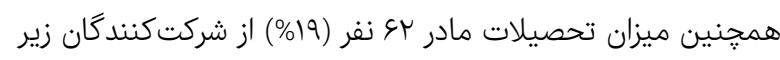

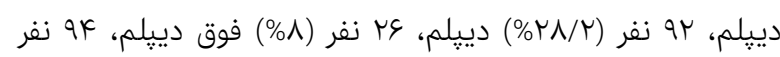

(\%rN/A)

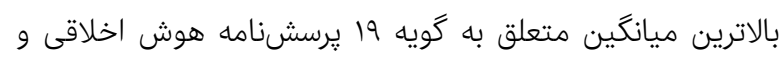

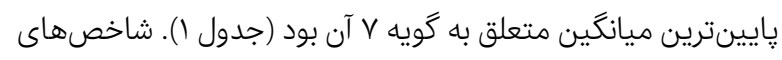

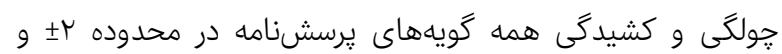

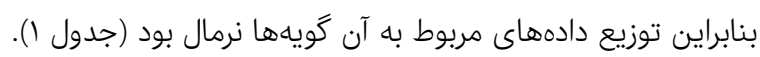

و حوزههاى متنوعى (اخلاقى، تربيتى، اقتصادى، جنسى و غيره) از

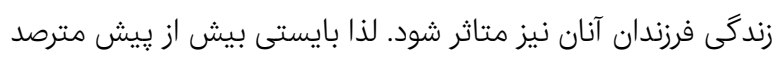

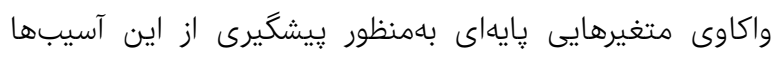

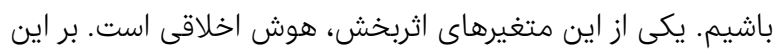

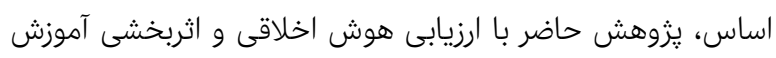

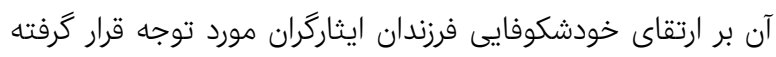
است تا زمينهاى براى شناخت سطح هوش آنقائ اخلاقى اين افراد فراهم

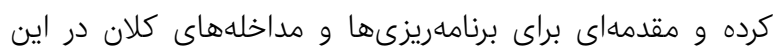
زمينه باشد. هوش اخلاقى توسط بوربا مطرح شده و مفهومى جديد است [4]. در

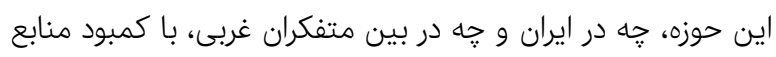

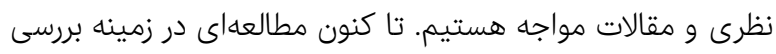

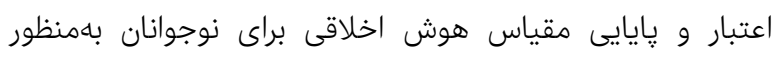

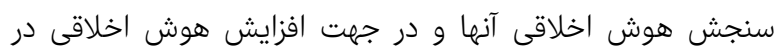

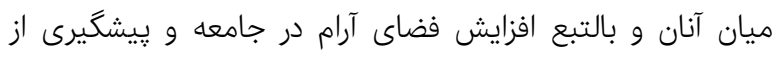

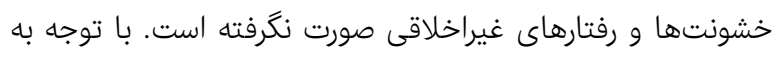

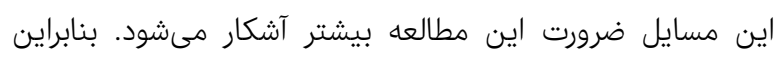

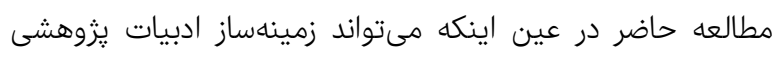

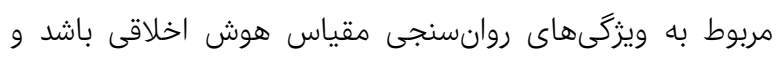

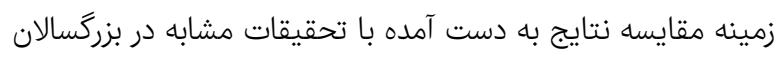

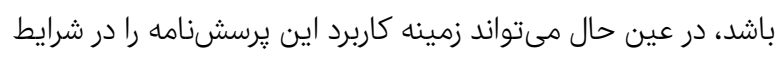

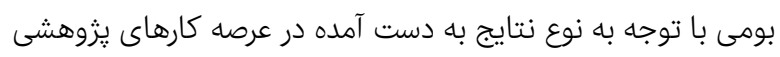

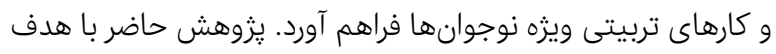

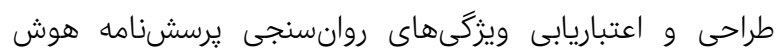
اخلاقى براى فرزندان نوجوان ايثاركران انجام شد.

\section{ابزار و روشها}

يزوهش، از نوع توصيفى و همبستگى با رويكرد آزمونسازى است.

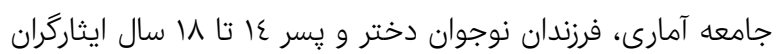

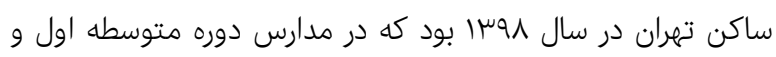

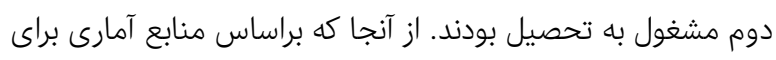

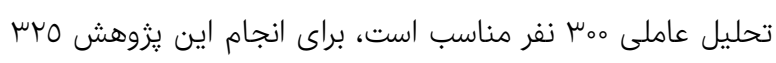

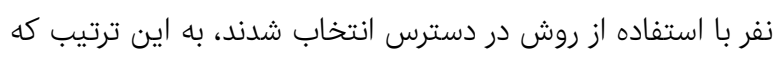

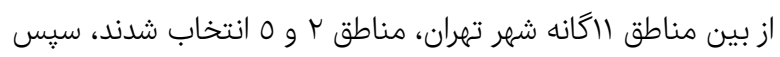

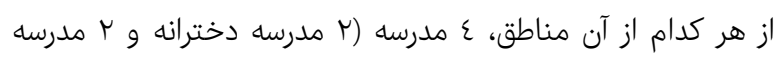
يسرانه) به شيوه تصادفى ساده انتخاب شد. آن مناطي،

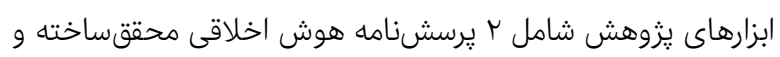

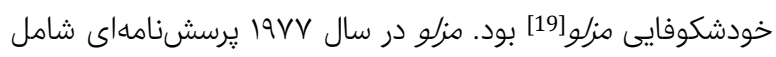

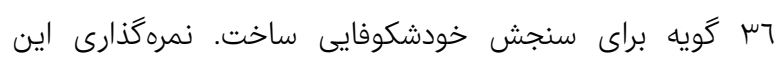

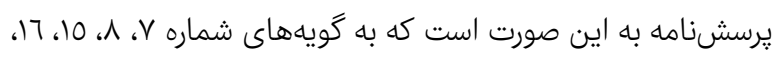

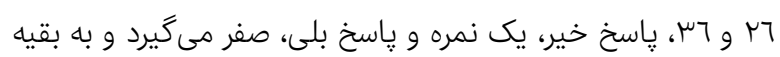

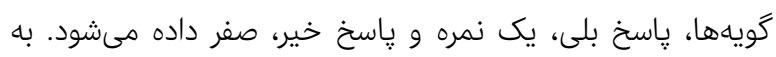

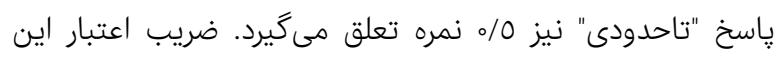

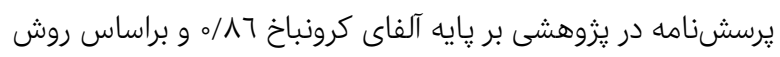




\begin{tabular}{|c|c|c|c|c|c|c|c|c|}
\hline \multirow[b]{2}{*}{ جولگى (كشيدگى) } & \multirow[b]{2}{*}{ ميانكين } & \multirow[b]{2}{*}{ گويه } & \multirow[b]{2}{*}{ جولخى (كشيدگى) } & \multicolumn{5}{|c|}{ جدول () نتايج ميانگين و نرمالى دادهها در هر يك از گويههاى هوش اخلاقى طراحىشده } \\
\hline & & & & ميانگين & كويه & جولخى (كشيدگى) & ميانگين & كويه \\
\hline$(-I / T K)-0 / K K$ & $\mu / V \Lambda \pm I / I r$ & $\mathrm{Fq}$ & $(-\circ / \wedge \mu)-\circ / \lambda r$ & $\mu / / \kappa \pm 1 / 1 q$ & $r \Delta$ & $(-0 / 4 q)-0 / T 1$ & $\mu / Y K_{ \pm} \pm / \% V$ & 1 \\
\hline$(\circ / \circ\rangle)-\% / \circ \Lambda$ & $\mu / \circ \Delta \pm 1 / 19$ & $\omega_{0}$ & $(-0 / \& K) \circ / k q$ & $\mu / V Y \pm 1 / r \mu$ & Ke & $\left(-0 / M^{\mu}\right)$ ( -o/ & $\mu / \mu_{\circ} \pm 1 / l_{0}$ & r \\
\hline$\left(-0 / r_{0}\right)-0 / \mu r$ & $\mu / V_{0} \pm \circ / Q \Lambda$ & Q1 & $(-I / T)-1 / Y \Lambda$ & $\mu /|q \pm 1 / r|$ & $r Y$ & $(0 / R q)-0 / V^{\mu}$ & $\mu / \Lambda l \pm 1 / .9)$ & $\mu$ \\
\hline$(-\circ / \Gamma \Delta)-0 / 9 \vee$ & $F / \circ \pm 1 / \circ V$ & $\Delta r$ & $(0 / 91)-0 / \Gamma \mu$ & $\mu / \mathcal{E} \mid \pm I / \circ D$ & rA & $(-\circ / \Delta Y)-0 / \mu \Lambda$ & $\mu / V^{\mu} \pm$ ॥/Q & F \\
\hline$(-0 / 09)-0 / \pi \wedge$ & 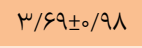 & $\Delta \mu$ & $\left(-0 / \mathcal{K}_{0}\right)-0 / \mu_{1}$ & $\mu / \mu \mu \pm 1 / / \mu$ & rq & 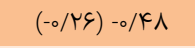 & $\mu / \varepsilon_{\circ} \pm 1 / \circ \mu$ & $\Delta$ \\
\hline$(\circ / G Y)-0 / Q T$ & $\mu / \varphi \pm 1 / T_{0}$ & $\Delta F$ & $\left(-0 / V_{0}\right)-0 / r \mu$ & $\Psi / \backslash \Lambda \pm I / \wedge$ & $\mu_{0}$ & $(-0 / Y Y)-0 / K G$ & $\mu / G r \pm 1 / \circ K$ & $\varepsilon$ \\
\hline$(0 / \wedge 9)-1 / 18$ & $\mu / \Lambda \circ \pm 1 / \circ r$ & $\Delta Q$ & $(0 / \mu I)-0 / 9 \Lambda$ & $\mu / ৭ १ \pm 1 / \circ \wedge$ & $\mu$ & $\left(\circ / 9_{0}\right)-0 / I V$ & $r / V \Lambda \pm I / r \mu$ & $\checkmark$ \\
\hline$(-0 / \xi \mu)-0 / \varangle \varphi$ & $/ 91 \pm I / 19$ & $\Delta S$ & $(-\circ / 10)-\circ / V \varepsilon$ & $\mu / q_{ \pm} \pm 1 / l_{0}$ & $\mu r$ & $(-\circ / \Delta Y)-0 / \& V$ & 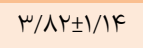 & $\wedge$ \\
\hline$(\circ / 19)-0 / V \varphi$ & $\mu / \wedge K_{ \pm} \pm / / \mu$ & $\Delta r$ & $(-0 / \mu q) \circ / 9 q$ & $\mu / \wedge \bigvee \pm 1 / \circ \varphi$ & $\mu \mu$ & $(-\circ / Y V)-\circ / V Q$ & $\mu / \mu \bigvee \pm 1 / \circ F$ & 9 \\
\hline$(-0 / K Y) \circ / Q 1$ & $\mu / q 1 \pm 1 / \circ \infty$ & $\Delta \Lambda$ & $(-\circ / V \mathcal{K})-\circ / \mu^{\mu}$ & 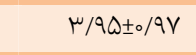 & $\mu F$ & $(-0 / R q)-0 / \mu k$ & $\mu / V_{\circ \pm} \pm / q$ & 10 \\
\hline$(-\circ / / K) \circ / Q V$ & $\mu / V \Delta \pm / ৭ ৭$ & $\Delta 9$ & $\left(-0 / \Lambda_{0}\right)--_{0} / \mu V$ & $r / \Delta q \pm 1 / I r$ & $\mu \Delta$ & $(0 / 09)-0 / \Delta r$ & $\mu / \Delta \Lambda \pm 1 / \Lambda K$ & 11 \\
\hline$(0 / 19)-0 / 91$ & $\Psi / V I \pm 1 / \circ \Delta$ & $\varepsilon_{0}$ & $(-\circ / \mu Y) \circ / T K$ & 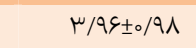 & w & $(\circ / T \Lambda) \circ / \Delta \mu$ & $\Psi / V K \pm 1 / 01$ & ir \\
\hline$(-\circ / \mu r)-0 / g \mu$ & $\mu / V \varepsilon \pm 1 / \diamond \Lambda$ & 91 & $\left(-\circ / \mathcal{F}^{\mu}\right)-\circ / V_{0}$ & $\mu / V \varepsilon \pm 1 / \circ \mu$ & $\mu \vee$ & $(-\circ / \% r)-\circ / \wedge r$ & $r / 0 \& \pm 0 / q r$ & Ir \\
\hline$(\circ / \Delta K)-0 / \varphi_{0}$ & $\mu / \Delta V \pm V / T I$ & \&r & $(\circ / 4 \mid)-0 / 0 \Delta$ & $\Psi / \wedge \vee \pm I / \Lambda Q$ & щᄉ & $(-0 / 91)-0 / 10$ & $\mu / l \pm 1 / \circ \Lambda$ & If \\
\hline$(-\circ / \% \mathcal{K}) \circ / \Delta \mu$ & $r / \varepsilon \mid \pm 1 / \circ r$ & $\varepsilon \mu$ & $(1 / T r)-0 / K G$ & r/VI士。/qr & $\mu q$ & $(-\circ / \circ Q) \circ / \mathbb{K} V$ & $\mu / V \tau_{ \pm} / q 9$ & 10 \\
\hline$(0 / \mathbb{K} Q)-0 / \mathbb{K}$ & $\mu / \varsigma \Delta \pm / ৭ q$ & sF & $(-\circ / 91)-0 / \Delta r$ & $\Psi / \Delta K \pm I / T I$ & $k_{0}$ & $(0 / T K)-0 / \Delta G$ & $\mu / \& V \pm 1 / \circ \Delta$ & 19 \\
\hline$(\circ / Q K)-0 / R \Delta$ & $\mu / \Delta \Lambda \pm 1 / \circ \mu$ & \&Q & $\left(-\circ / \Delta_{0}\right)-0 / \circ \Lambda$ & $\kappa / \Lambda \Lambda \pm I / / \mu$ & FI & $(-0 / \Lambda I)-0 / \mathcal{F} \Lambda$ & $\mu / \vee q \pm 1 / \circ \circ$ & iv \\
\hline$(-\circ / V I)-0 / K_{k}$ & $\mu / 4 \mid \pm I / 19$ & \&8 & $(-\circ / Y I)-\circ / \Delta Q$ & 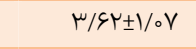 & Fr & $(-\circ / \circ \mathcal{F})-0 / \mu \Delta$ & $\mu / \vee \varepsilon_{ \pm} / 9 \Lambda$ & 11 \\
\hline$(-\circ / F F)-0 / \Delta q$ & $\Psi / \Delta V \pm I / I V$ & $\& V$ & $(-0 / \lambda Y)-0 / V K$ & $\mu / q \mu_{ \pm 1 / \circ} k$ & $\mathrm{kr}$ & $(\circ / \Delta Q)-1 / \circ \mu$ & $r / \circ 9 \pm 1 / \circ r$ & 19 \\
\hline$\left(-0 / Y^{\mu}\right)-0 / \Delta \Lambda$ & $\mu / १ \omega \pm 。 / q \mu$ & $8 \Lambda$ & $(-\circ / / V) \circ / \& V$ & $\mu / V Y \pm \circ / q \Delta$ & $F F$ & $(-\circ / \wedge \varphi)-0 / \mu q$ & $\mu / \varepsilon \uparrow \pm 0 / \Lambda q$ & $r_{0}$ \\
\hline$\left(-\circ / \mu^{\mu} V\right)-0 / \varphi \varphi$ & $\mu / V \varepsilon_{ \pm} / / \Lambda Q$ & 99 & $(-0 / \mu \gamma)-0 / k \mu$ & $\Psi / \Delta r \pm I / Y K$ & $F \Delta$ & 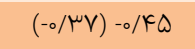 & $\mu / \Delta q \pm 1 / \circ \mu$ & $M$ \\
\hline$(-\circ / / \Gamma)-0 / \wedge q$ & 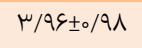 & $V_{0}$ & $(0 / \mu \varepsilon)-0 / V 1$ & $\mu / V \Delta \pm 1 / \tau_{0}$ & KE & $(-\circ / r \Lambda) \circ / \varepsilon \Delta$ & $\mu / \Lambda \bigvee \pm I / \diamond \Lambda$ & rr \\
\hline- & - & - & $\left(\circ / \mu^{\mu}\right)-0 / \xi \Lambda$ & $\mu / V V \pm 1 / \circ{ }^{k}$ & $\mathrm{FV}$ & $(-\circ / \Delta \mu)-\circ / \measuredangle ६$ & 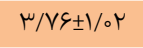 & س \\
\hline- & - & - & $(-0 / 01)-0 / 44$ & $\mu / V r \pm 1 / o l$ & FA & $(-\circ / \circ \Lambda) \circ / \mu r$ & $r / ৭ \& \pm 1 / / K$ & MF \\
\hline
\end{tabular}

بارهاى عاملى جرخشيافته در تحليل مولفههاى اصلى نشان داد كه

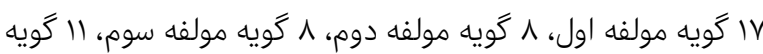

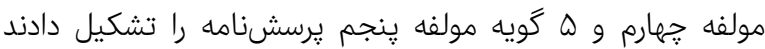

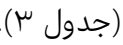

در ادامه يس از استخراج مولفهها، براساس اشتراك معانى گويهها

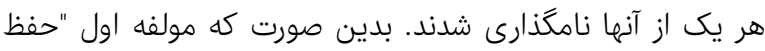
عزت ديكران"، مولفه دوم "يايبندى به اصول"، مولفه سوم "حساسيت

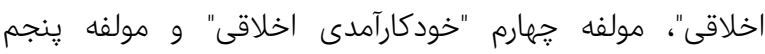
"توانمندى ايكو" نامگذارى شدند.

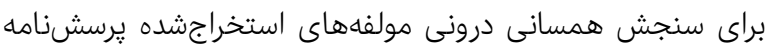
هوش اخلاقى، ضريب آلفاى كرونباخ مولفهها با استفاده از فرمول هولئل

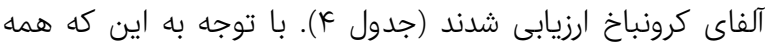

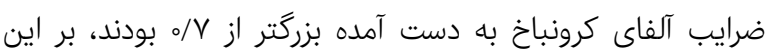

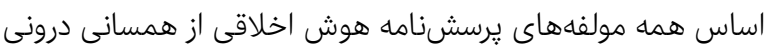
مطلوبى برخوردار بودند. نتايج ضرايب همبستگى بين مولفههاى يرسشنامدامه هوش اخلاقى

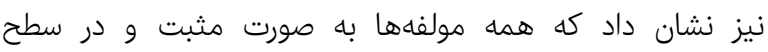

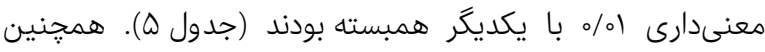

شاخص كايسر- مير- اوليكن (KMO) برابر با 101/ه و شاخص

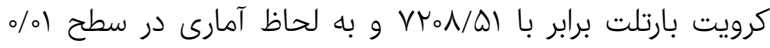

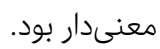
19 مولفه با ارزش ويزه بزركتر از يك استخراج شد كه تقريبا 79\% از

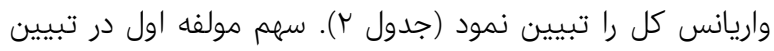

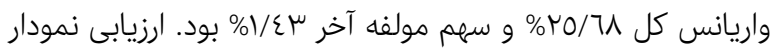

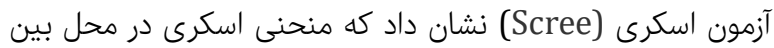

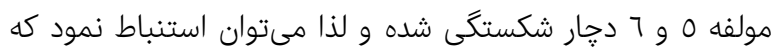

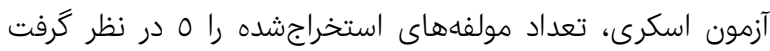

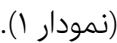

يس از تعيين تعداد مولفهها، تحليل براى بار دوم و با تثبيت تعداد

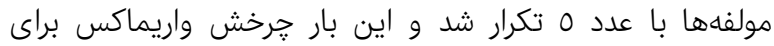

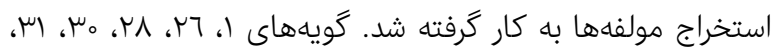

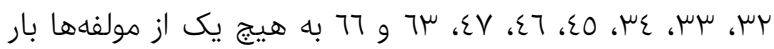

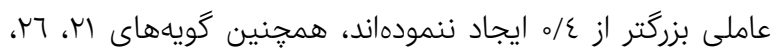

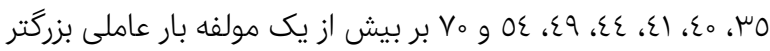

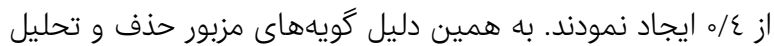
بار ديكر تكرار شد. 


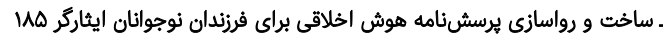

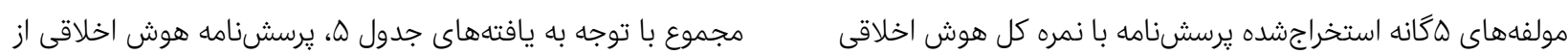

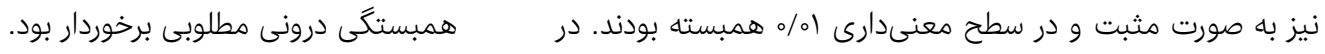

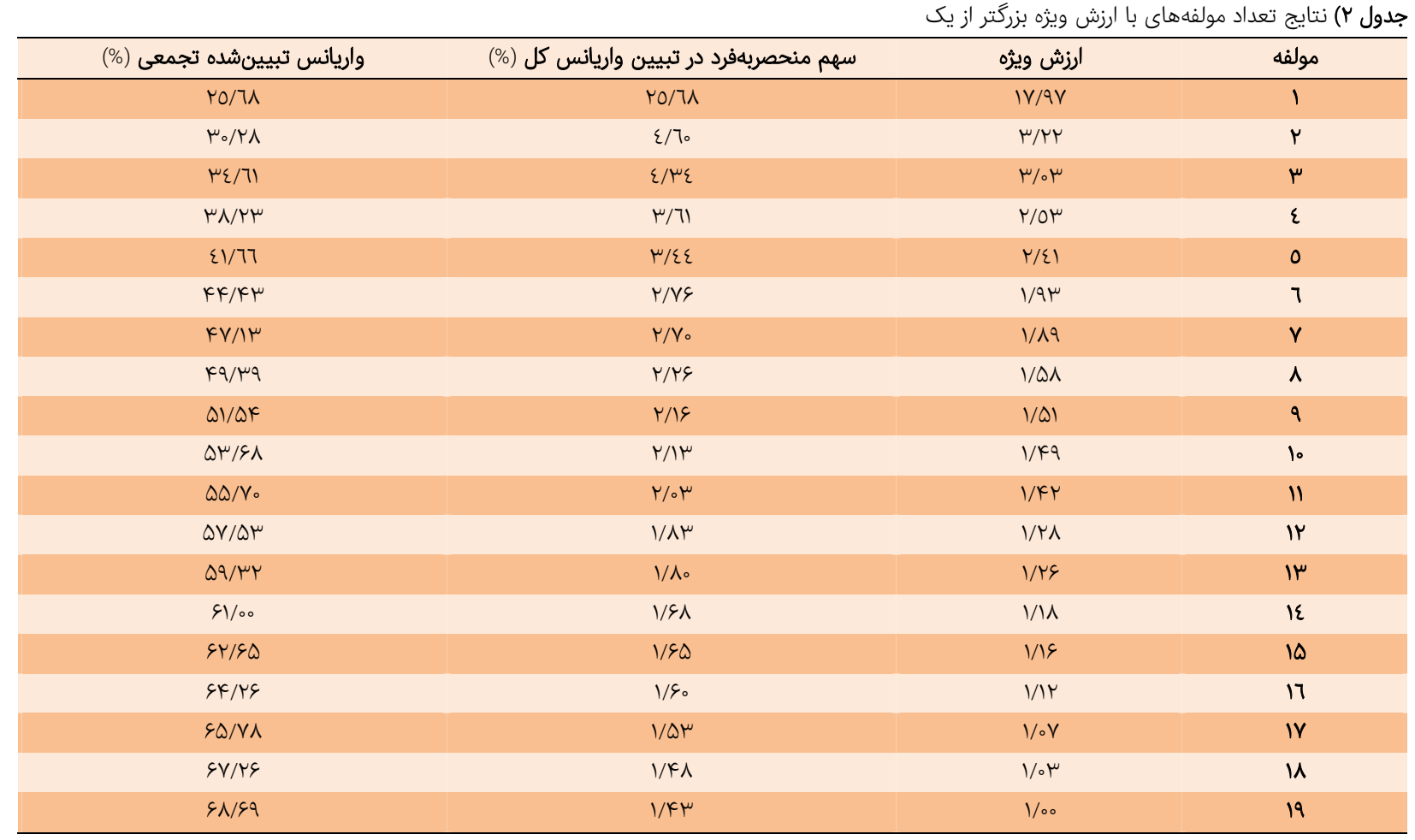

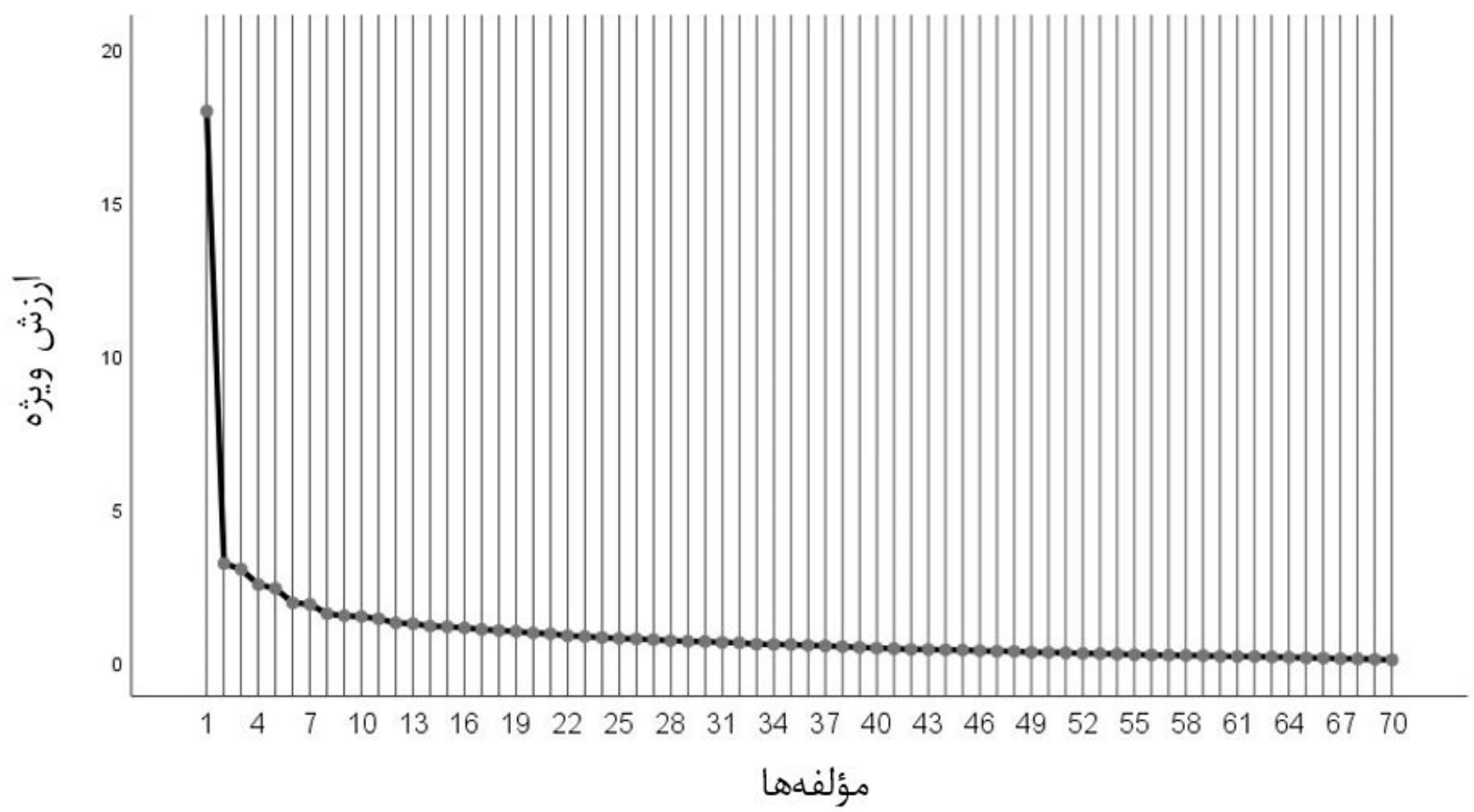

نمودار () نتايج آزمون اسكرى در تعيين تعداد مولفهها 


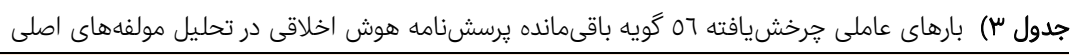

\begin{tabular}{|c|c|c|c|c|c|c|}
\hline \multirow{2}{*}{ 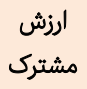 } & \multicolumn{5}{|c|}{ 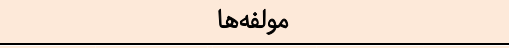 } & \multirow{2}{*}{ كويهها } \\
\hline & إنجم & جهارم & 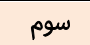 & دوم & اول & \\
\hline o/DSI & & & & & $\frac{0}{\circ / V / \mu}$ & 10. نسبت به ديكران صرفنظر از فرهنگ و سن و غيره، بردبارى نشان مىدهم. \\
\hline /owo & & & & & o/9V४ & سم. براى شناختن افرادى با ييشينه و باورهايى متفاوت از خود، گشادهرو هستم. \\
\hline$\circ / \varepsilon १ \wedge$ & & & & & $\circ / 9 \vee \Delta$ & 09. بجاى تاكيد بر تفاوتها، بر صفات مثبت افراد تاكيد مىكنم. \\
\hline O/DKA & & & & & o/9६V & 1ـ. عبارتهايى را به كار مىبرم كه به ديكران اعتبار مىبخشد. \\
\hline ./DFA & & & & & $\circ / 94$. & Tr هr. به بزرگسالان و افراد بانفوذ، احترام مى گذارم. \\
\hline$\circ / F \Delta Q$ & & & & & $\circ / 9 \circ V$ & FF F مايلم مياندارى كنم تا نيازهاى همه برآورده شود. \\
\hline$\circ / k k_{0}$ & & & & & o/צ.r & هV \\
\hline o/9וr & & & & & ०/Q9K & 19. از فرصت خدمت به ديكران خوشحال مىشوم. \\
\hline 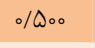 & & & & & ०/DSG & ه1. صرفنظر از فرهنگ، نزاد، ظاهر، ناتوانى و غيره افراد، با آنان مهربان و گشادهرو هستم. \\
\hline o/ $/ 41$ & & & & & $\circ / 019$ & هه. از آدمهاى ستمديده دفاع مىكنم و اجازه بىعدالتى را نمىدهم. \\
\hline . $/ F \Delta R$ & & & & & $\circ / \Delta \cdot 1$ & F F א. به فردى كه نياز به كمك دارد يا غمكين است، خالصانه توجه نشان مىدهم. \\
\hline$\circ / 4 \& V$ & & & & & o/kqr & •. از قضاوتكردن، طبقهكردن و غيره ديكران خوددارى مىكنم. \\
\hline$\circ /$ « $\wedge 9$ & & & & & $0 / 4 \wedge 9$ & هם. سعهصدر دارم و يیش از اينكه نظرى بدهم به تمام جنبهها كوش مىكنم. \\
\hline ./WG。 & & & & & $0 / 4 \& D$ & צه. از به زبان آوردن جوكها يا عبارتهايى كه ديكران را خوار و خفيف مىكند، خوددارى مىكنم. \\
\hline o/TAK & & & & & $0 / k 4 G$ & Fr Fr در رفتار ديكران، معمولاً رفتارهاى مهربانانه و عاطفى را مشاهده مىكنم. \\
\hline$\circ / \mu q \circ$ & & & & & $0 / k F 1$ & 11. تلاش مى كنم مسائل را منصفانه و مسالمتآميز حل كنم. \\
\hline o/rq & & & & & o/KMF & •ه. به نزد افرادى مىروم كه منزوى يا طرد شدهاند. \\
\hline$\circ / \Delta M$ & & & & o/99ฬ & & qس. بىتعصب و بدون اينكه حرف ديكران را قطع كنم، به عقايد آنها كوش مىكنم. \\
\hline o/kqY & & & & o/\&ar & & 99. با پِيروى از قوانين، بازى مىكنم و وسط راه، بازى را به نفع خودم تغيير نمىدهم. \\
\hline$\circ / \notin q \mu$ & & & & o/दkr & & r. عبورانه منتظر نوبتم مىمانم. \\
\hline o/kIT & & & & $\circ / \Delta M$ & & وس. با دارايىهاى خود و ديكران، با احترام رفتار مىكنم. \\
\hline 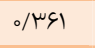 & & & & $\circ / \Delta 1 \Lambda$ & & rr. براى نوبت خود صبر مىكنم و تقريباً هرگز بىاجازه وارد جايى يا مزاحم كسى نمىشوم. \\
\hline$\circ / \mu k \mu$ & & & & $\circ / K \Lambda_{0}$ & & FV . بدون تشويق يا يادآورى ديكران، در وسايلم با ديكران شريك مىشوم. \\
\hline o/Arg & & & & $0 / k<q$ & & و غيره) و وقى با ديكران صحبت مىكنم حالت بدنىام همراه با احترام است (رو برنمىگردانم، يوزخند نمىزنم \\
\hline $0 / \& \mu \gamma$ & & & & $0 / k \mu_{1}$ & & بـ كا. بدون نياز به تذكر ديكران، عبارتهاى محترمانهاى مانند "عذرمىخواهم"، "خواهش مىكنم" و غيره را \\
\hline$\circ / \Delta \mu \mu$ & & & $\circ / V M I$ & & & V. وقتى كسى دجار درماندگى باشد، گريه مىكنم يا ناراحت مىشوم. \\
\hline /DQT & & & $\circ / \mathrm{VII}$ & & & 1. وقتى با كسى ظالمانه يا غيردوستانه رفتار شده باشد، ناراحت مىشوم. \\
\hline$\circ / \mathrm{krA}$ & & & $\circ / 9 \%$ & & & r. نسبت به نيازها و احساسات ديكران، حساسيت نشان مىدهم. \\
\hline 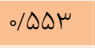 & & & $\circ / \varphi_{\circ} \Lambda$ & & & 19. اكر بهواسطه من، كسى آسيب عاطفى يا جسمى ببيند، سعى مىكنم آن را جبران كنم. \\
\hline $0 / 4 \circ 9$ & & & $\circ / \Delta \& \Delta$ & & & IV. براى رفتار نامناسبم، احساس گناه يا شرم مىكنم. \\
\hline . $/$ \& $\mu$ & & & $\circ / \Delta F 1$ & & & 11. به اشتباهاتم اعتراف كرده و عذرخواهى مىكنم. \\
\hline $0 / K \& 4$ & & & o/kAr & & & rا. متوجه اشتباهبودن رفتارم مىشوم و توضيح مىدهم كه جرا آن رفتار اشتباه است. \\
\hline$\circ /$ MrF & & & $0 / k r_{0}$ & & & 9. به درك ديدگاههاى ديكران، تمايل نشان مىدهم. \\
\hline o/KAK & & /DSA & & & & F. به سرعت، حالتهاى جهره ديكران را درك مىكنم و واكنش مناسب نشان مىدهم. \\
\hline o/krr & & $\circ / \Delta \Delta \Lambda$ & & & & يايبند ميىمانم. ر راه درست رشناسم و حتى اگر براى عمل خلاف آن از سوى ديكران تحت فشار باشم به كار درست، \\
\hline ./WG。 & & $\circ / \Delta K \mu$ & & & & ". نشانههاى غيركلامى ديكران مثل اشارات، حالتهاى جهره و لحن صدا را درست تشخيص مىدهم. \\
\hline$\circ / \mu q \mu$ & & $\circ / \Delta F \mu$ & & & & ا 1. مىتوانم احساسات افراد را از طريق كلام آنها بشناسم. \\
\hline$\circ / \mu \mathrm{V}$ & & o/DKr & & & & هـ حالت درماندگى ديكران را تشخيص مىدهم و واكنش مناسب نشان مىدهم. \\
\hline$\circ / \mu \vee \varphi$ & & /arq & & & & 10. بيامدهاى رفتار نامناسب خود را تشخيص مىدهم. \\
\hline o/krt & & $\circ / \mathbb{F \wedge}$ & & & & سץ. قادرم تمايلات و نيازهايم را بدون كمك بزركسالان، تنظيم و هدايت كنم. \\
\hline$\circ /$ rqV & & o/kVE & & & & 1.ا. وقتى اشتباه مى كنم، كناهم را مىيذيرم و سعى نمى كنم آن مشكل را به ديكران نسبت دهم. \\
\hline$\circ / \mu \Delta S$ & & $\circ / K \varepsilon_{0}$ & & & & \&. از نظر ديكران، احساسات آنها را درك مى كنم. \\
\hline$\circ / K r \Delta$ & & 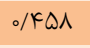 & & & & •r. مىدانم كه جطور يك رفتار اشتباه را به رفتارى صحيح تبديل كنم. \\
\hline$\circ / \mu k 1$ & & $\circ / K \mu \Delta$ & & & & سا. صادق هستم و ديكران مىتوانند روى حرفهايم حساب كنند. \\
\hline / & $\circ / \mathrm{V} /$ & & & & & qج. به ندرت به يادآورى، توبيخ يا هشدار براى رفتار مناسب نياز دارم. \\
\hline$\circ / 491$ & $8 / 77$ & & & & & MF. زمانى كه هيجانزده، مستاصل يا عصبانى هستم، به راحتى آرام مىگيرم. \\
\hline$\circ / 411$ & $\circ / 7 r r$ & & & & & هQT. به ندرت دهار خشم مىشوم؛ طغيانهاى هيجانى ندارم و از كوره در نمىروم. \\
\hline ו ו ו & /oro & & & & & TY Y. به ندرت بدون تفكر، دست به عمل مىزنم. \\
\hline$\circ / \mu \wedge \mu$ & $\circ / \varepsilon 79$ & & & & & FF أ. در مورد اينكه جكونه درست رفتار كنم به ندرت به تذكرات افراد نياز دارم. \\
\hline
\end{tabular}




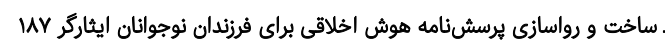

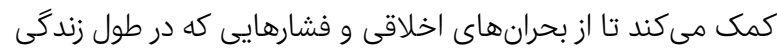

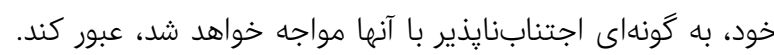

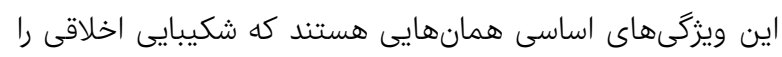

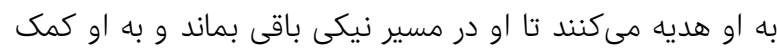
مى كند تا به صورت اخلاقى رفتار كند"[22].

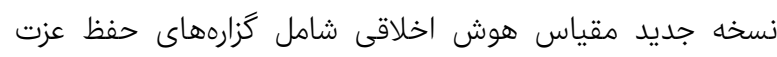

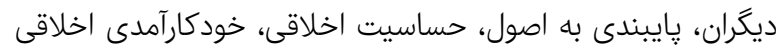

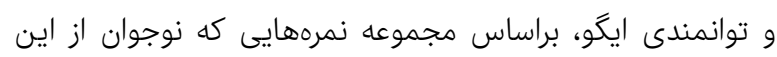

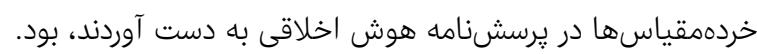
جهارجوب نظرى تحقيق حاضر براساس عقايد مدل بوربا [22] شكل

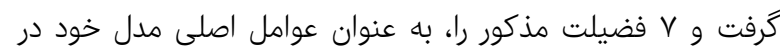

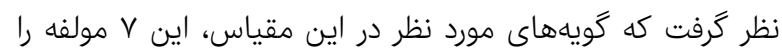

نسنجيد. نتايج تحقيق با استفاده از آمارههاى توصيفى و استنباطى نشان داد

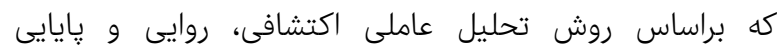

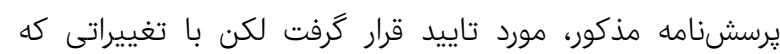

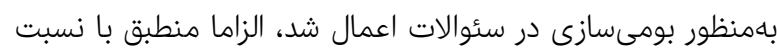

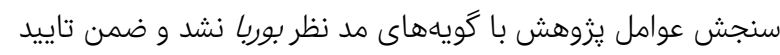

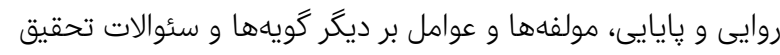

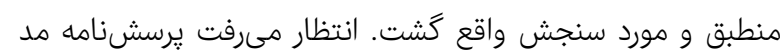

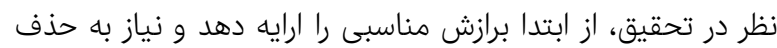

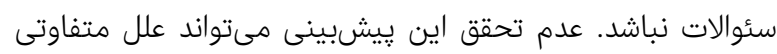

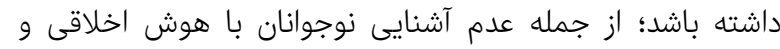

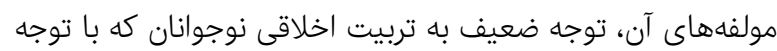
به تاكيد دين بر اخلاق، در جامعه اسلامى انتظار بيشترى از والدين نوانين

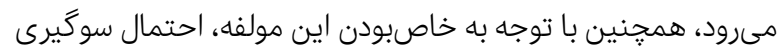

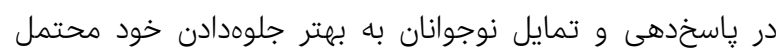

اين يزوهش با محدوديتهايى همراه بود؛ از جمله اينكه همكارى

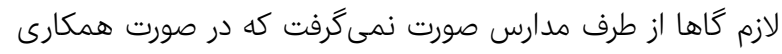

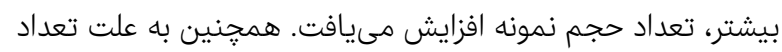

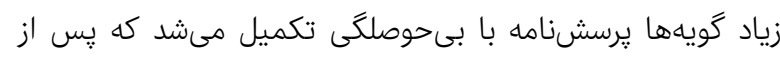

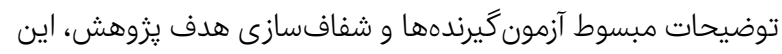

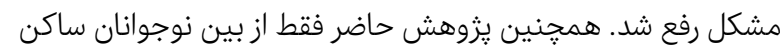

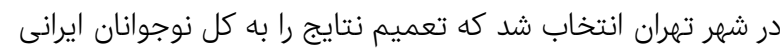
محتاطانه مى دند.

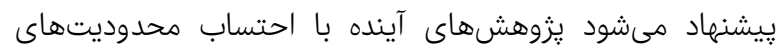
ذكرشده با توجه به مقياس حاضر كه منطبق بادوه شرايط بومى آماده

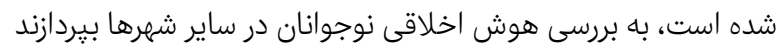

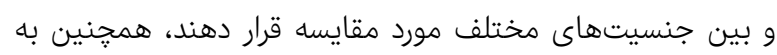

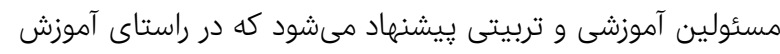
و تقويت هوش اخلاقى نوجوانان، برنامهريزى كنند.
جدول F) نتايج سنجش همسانى درونى مولفهاى استخراجشده يرسشنامه

\begin{tabular}{|c|c|c|c|}
\hline آلفاى كرونباخ & ميانكين & تعداد گويه & هوش اخلاقى \\
\hline.$/ 901$ & $G K / \mathcal{K}_{\circ} \pm 11 / \circ D$ & IV & حفظ عزت ديكران \\
\hline$\circ / \vee \wedge 9$ & $r q / \wedge) \pm \Delta / V)$ & $\wedge$ & پايبندى به اصول \\
\hline$\circ / V V Q$ & $r \Lambda / r \circ \pm \Delta / \Delta \mu$ & $\wedge$ & حساسيت اخلاقى \\
\hline ॰/VGq & $\kappa_{0} / \varepsilon \vee \pm \varepsilon / 01$ & 11 & خودكارآمدى اخلاقى \\
\hline ०/VYG & $|Q / \varphi| \pm \psi / V \mu$ & $\Delta$ & توانمندى ايكو \\
\hline o/qur & 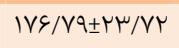 & $\mathrm{kq}$ & نمره كل هوش اخلاقى \\
\hline
\end{tabular}

ميانكين و آلفاى كرونباخ متغير خودشكوفايى به ترتيب برابر

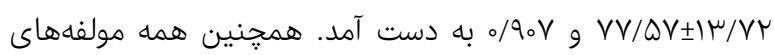
استخراجشده يرسشنامه هوش اخلاقى با خودشكوفايى به صورت

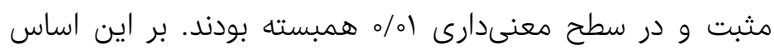

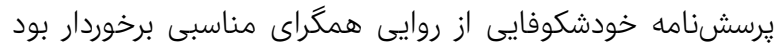

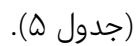

جدول ه) نتايج ضرايب همبستگى بين مولفههاى يرسشنامه هوش اخلاقى

$(p<\circ / 0))$

\begin{tabular}{|c|c|c|c|c|c|c|c|}
\hline \multirow[t]{7}{*}{$V$} & 8 & $\Delta$ & k & $\mu$ & $r$ & 1 & متغير \\
\hline & & & & & & 1 & 1. حفظ عزت ديكران \\
\hline & & & & & 1 & o/\&K & r. پايبندى به اصول \\
\hline & & & & 1 & $\circ / \mu$ & $0 / 4 \varepsilon$ & "َ. حساسيت اخلاقى \\
\hline & & & 1 & $0 / k F$ & $\circ / K_{0}$ & $o / k F$ & F F خودكارآمدى اخلاقى \\
\hline & & 1 & D & $0 / T K$ & $\circ / 4 q$ & $\circ / 4 q$ & هـ ــ توانمندى ايكو \\
\hline & 1 & $\circ / F a$ & $\circ / \mathrm{V}$ & $0 / 99$ & $\circ / V Q$ & ०/19 & צ. نمره كل هوش اخلاقى \\
\hline 1 & $\circ / \Delta 1$ & $0 / Y Y$ & $o / \mu k$ & ס & $\circ / \Delta_{\circ}$ & $0 / 49$ & V V. ل خودشكوفايى \\
\hline
\end{tabular}

بحث

براساس نتايج نهايى و با توجه به كل شاخصهاى برازش مى بـوان

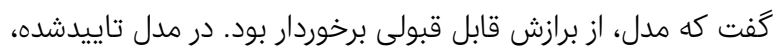

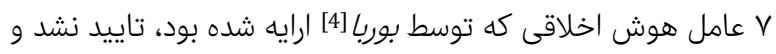

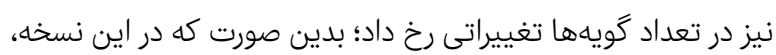
به 0 ب عامل تقليل يافت. بوربا [4] هوش اخلاقى را ظرفيت و توانيل يافيى فهميدن درست از غلط،

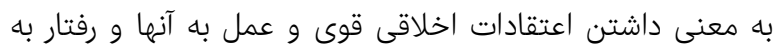

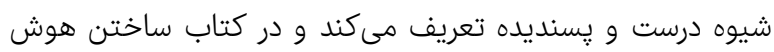

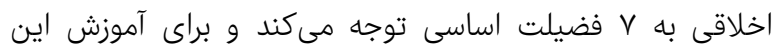

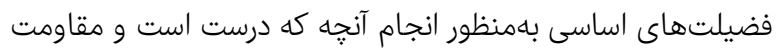

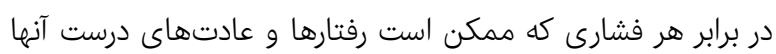

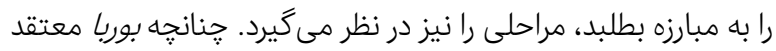

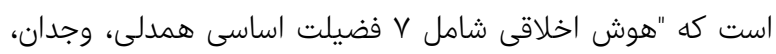
خويشتندارى، احترام، مهربانى، بردبارى و انصاف است كه لهامل فيه فرزند 
Longitudinal associations with romantic outcomes in emerging adulthood. J Adolesc. 2010;33(1):159-71.

8- Roelofs J, Onckels L, Muris P. Attachment quality and psychopathological symptoms in clinically referred adolescents: The mediating role of early maladaptive schema. J Child Fam Stud. 2013;22(3):377-85.

9- Kawabata Y, Alink LRA, Tseng WL, Van IJzendoorn MH, Crick NR. Maternal and paternal parenting styles associated with relational aggression in children and adolescents: A conceptual analysis and meta-analytic review. Dev Rev. 2011;31(4):240-78.

10- Pargament KI, McCarthy S, Shah P, Ano G, Tarakeshwar N, Wachholtz A, et al. Religion and HIV: A review of the literature and clinical implications. South Med J. 2004;97(12):1201-9.

11- Chow KW, Lo BCY. Parental factors associated with rumination related metacognitive beliefs in adolescence. Front Psychol. 2017;8:536.

12- Hill PC, Pargament KI. Advances in the conceptualization and measurement of religion and spirituality: Implications for physical and mental health research. Am Psychol. 2003;58(1):64-74.

13- Turner N, Barling J. Transformational leadership and moral reasoning. J Appl Psychol. 2002;87(2):304-11.

14- Flite CA, Harman LB. Code of ethics: principles for ethical leadership. Perspect Health Inf Manag. 2013;10(Winter):1d.

15- Rigby K, Slee PT, Martin G. Implications of inadequate parental bonding and peer victimization for adolescent mental health. J Adolesc. 2007;30(5):801-12.

16- Nash ST. The changing of the gods: abused Christian wives and their hermeneutic revision of gender, power, and spousal conduct. Qual Soc. 2006;29(2):195-209.

17- Liu AM, Fellows R, Ng J. Surveyors' perspectives on ethics in organizational culture. Eng Constr Archit Manag. 2004;11(6):438-49.

18- Coles R. The moral intelligence of children. Fam Court Rev. 1998;36(1):90-5.

19- Maslow AH. Critique of self-actualization theory. J Humanist Educ Dev. 1991;29(3):103-8.

20- Mousavi SH, Dargahi H. Ethnic differences and motivation based on Maslow's theory on Iranian employees. Iran J Public Health. 2013;42(5):516-21.

21-Amiri Y. Investigating the needs of school principals in Tehran based on Maslow's hierarchy of needs [Dissertation]. Tehran: Shahid Beheshti University; 1996. [Persian]

22- Borba M. Parents Do make a difference. San Francisco: Jessy-Bass; 1999.
مقياس هوش اخلاقى طراحىشده به عنوان مدلى براى سنجش

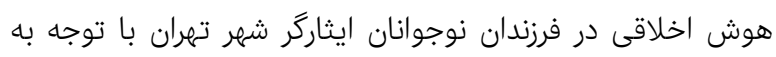
تغييرات اجتماعى-شناختى در جامعه ايرانى، ابزارى پايا و روا است.

تشكر و قدردانى: محققان از مسئولان محترم يزوهشكده مهندسى و علوم

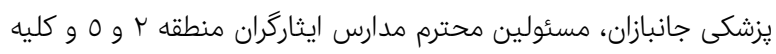

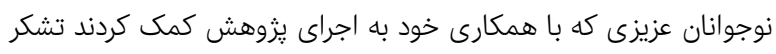

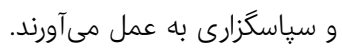

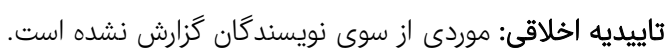
تعارض منافع: تعارض منافعى وجود ندارد.

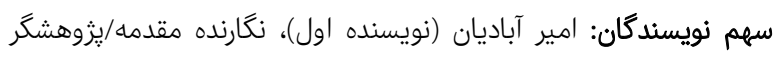

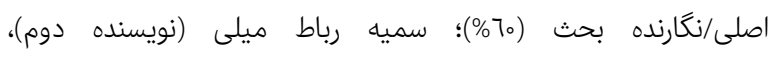

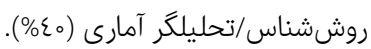

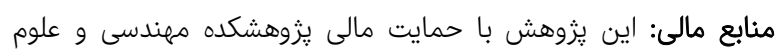
يزشكى جانبازان انجام شده است.

منابع 1- Shahabi M, Amin Yazdi S A, Mashhadi A, Hasani J. The Role of Religious Attitude in Coping with Psychological Distress and Emotion Regulation Difficulties of UT Students. J Res Relig Health. 2017;3(4):32-47. [Persian]

2- Beyrami M, Hashemi T, Fathi Azar E, Alayi P. The effectiveness of shame management training based on PEGS program in reducing bullying of female adolescents. Q J New Psychol Res. 2015;10(3):1-23. [Persian] 3- Bazoolnejad M, Robatmili S. Correlation of parental perception and its components with attachment style and tendency to communicate with the opposite sex in veterans' daughters. Iran J War Public Health. 2018;10(2):91-7. [Persian]

4- Borba M. Building moral intelligence: The seven essential virtues that teach kids to do the right thing. New York: Wiley; 2001.

5- Borba M. The step-by-step plan to building moral intelligence. New York: Jossey-Bass; 2005.

6- Lennick D, Kiel F. Linking strong moral principles to business success [Dissertation]. Pennsylvania: Wharton School of the University of Pennsylvania; 2005.

7- Seiffge-Krenke I, Overbeek G, Vermulst A. Parentchild relationship trajectories during adolescence: 